From the Carnegie Mellon University; Magee Womens Hospital; University of Pittsburgh Cancer Centers, University of Pittsburgh Medical Center, Pittsburgh, PA; Emory University, Atlanta, GA.

Submitted September 21, 2004 accepted March 8, 2005

Supported by National Institutes of Health grants CA64711, CA103730 HL65111, and HL65112.

Presented in part at the annual meeting of the American Psychological Association, Honolulu, $\mathrm{HI}$ July 28-August 1, 2004

Authors' disclosures of potential conflicts of interest are found at the end of this article.

Address reprint requests to Michael F. Scheier, Department of Psychology, Carnegie Mellon University, Pittsburgh PA, 15213; e-mail: scheier@cmu.edu.

(C) 2005 by American Society of Clinical Oncology

0732-183X/05/2319-4298/\$20.00

DOI: $10.1200 / J C O .2005 .05 .362$

\title{
Interventions to Enhance Physical and Psychological Functioning Among Younger Women Who Are Ending Nonhormonal Adjuvant Treatment for Early-Stage Breast Cancer
}

Michael F. Scheier, Vicki S. Helgeson, Richard Schulz, Suzanne Colvin, Sarah Berga, Michael W. Bridges, Judy Knapp, Kristina Gerszten, and William Scott Pappert

$$
\begin{array}{llllllll}
\text { A } & \text { B } & \text { S } & \text { T } & \text { R } & \text { A } & \text { C } & \text { T }
\end{array}
$$

\section{Purpose}

To conduct a clinical trial to determine if an educational intervention and a nutritional intervention could enhance physical and psychological functioning among younger women completing treatment for early-stage breast cancer.

\section{Patients and Methods}

Younger women (50 years of age or younger, $N=252$ ), within 2 months of having completed active nonhormonal adjuvant therapy, diagnosed with stage 0 , I, or II breast cancer with 10 or fewer positive lymph nodes were randomly assigned to a three-arm clinical trial. Women in the control arm of the trial received standard medical care. Women in the two active arms received either an educational intervention, designed to provide information about their illness and enhance adjustment, or a nutritional intervention, designed to promote a more healthy diet. Primary end points included mental functioning, physical functioning, and depressive symptoms. Women were assessed before random assignment, 4 months later (immediately postintervention), and 13 months later (9 months postintervention).

\section{Results}

Participants assigned to the two active treatment arms had significantly less depressive symptomatology and better physical functioning by 13-month follow-up (differences between the two active arms were nonsignificant). These effects were primarily accounted for by changes in intrusive thoughts, concerns regarding cancer recurrence and mortality, self-concept perceptions, and self-efficacy expectations.

\section{Conclusion}

Tailored psychosocial interventions can be effectively designed to enhance adjustment among younger women who are completing nonhormonal adjuvant therapy.

J Clin Oncol 23:4298-4311. (c) 2005 by American Society of Clinical Oncology

\section{INTRODUCTION}

A number of studies have examined the impact of psychosocial interventions on adjustment to breast cancer. ${ }^{1-15}$ Although somewhat mixed in their results, these studies have generally found positive outcomes, with women in the intervention groups often showing enhanced physical functioning and psychological adjustment, and sometimes better biologic functioning as well. ${ }^{15}$
To date, interventions have been constructed largely without regard to the age of the recipients receiving the intervention. Although some studies do report that age has little influence on adjustment, ${ }^{16-19}$ other studies have found that younger women are at greater risk for psychological distress. ${ }^{20-26} \mathrm{It}$ also appears that younger women face a somewhat different set of challenges and have a different set of needs. ${ }^{27,28}$ These considerations suggest that it might be advantageous to devise 
and evaluate interventions that are specifically targeted toward younger women. This is a major aim of the present research.

A second set of considerations concerns the timing at which psychosocial interventions are typically delivered. Again, there is considerable uniformity in the existing literature. Most interventions have been targeted toward the initial diagnosis and treatment period. Accumulating research suggests, however, that distress and cancer concerns may increase in prevalence at the time at which traditional modes of adjuvant treatment (ie, radiotherapy and chemotherapy) end. ${ }^{29-32}$ These considerations suggest that it might also be advantageous to design and evaluate interventions that are targeted to occur at the point at which women are completing treatment and returning to normal lifestyles. This is a second major aim of the present research.

Finally, it is not only important to determine that a particular intervention is successful, but it also is useful to know why it is successful. We explored the role of five psychological variables as potential mediators of the intervention effects. We chose these five variables because we believed that they were mechanisms targeted by the interventions. First, we examined self-efficacy as an explanatory variable because our interventions were aimed at providing people with knowledge and skills that should increase their confidence in their abilities to take care of themselves. ${ }^{13}$ Second, we examined intrusive thoughts about the illness because we believed that the information and skills provided would decrease the overall level of distress surrounding the illness, which should result in fewer intrusive illness-related cognitions. ${ }^{33-37}$ Third, we examined coping because one section of the education intervention targeted coping skills. The skills gained in the nutrition intervention might be expected to enhance aspects of coping, for example, active coping. Fourth, we believed that the information provided in both interventions would enhance women's feelings about their appearance and therefore their overall levels of femininity and sexual desirability. ${ }^{38-40}$ Thus, we examined feminine self-concept or body image as a mediator. Lastly, we examined the extent to which both interventions reduced cancer-related concerns. The information and skills provided by both interventions should reduce worries that are tied to cancer..$^{38-40}$

In the present study, younger women, within 2 months of having completed nonhormonal adjuvant treatment, were randomly assigned to a three-arm clinical trial. Women in the control arm of the trial received standard medical care. Women in one of the active arms received an education intervention, designed to provide them with information about their illness and its adverse effects. Women in the second active arm received a nutritional intervention, designed to provide them with strategies to adopt and adhere to a low-fat, high-fruit-and-vegetable eating pattern.

Education interventions have been used widely to enhance adjustment among women with breast cancer, ${ }^{13,14,41,42}$ and as such require little justification, although this is the first trial to focus such an intervention on younger women who are completing adjuvant treatment. The nutritional intervention is more novel. This intervention was chosen for three reasons. First, it reflects our belief that effective interventions work largely because they enhance feelings of selfefficacy and confidence. In principle, confidence can be bolstered in a variety of ways. For example, patients can be provided with information about their disease, its treatment, and how to cope with both (reflecting the normative offering of most education interventions), or patients can be provided with something concrete and proactive that they can $d o$ (ie, engage in a more healthy lifestyle by eating better). In our view, both sets of experiences should enhance the confidence that people have in their ability to deal with their situation effectively. We should note that our emphasis, imparted to the women, was on the fact that dietary changes influence overall health and well-being, not necessarily breast cancer progression. Second, the nutritional intervention was chosen because it was a more novel and interesting way to provide women with a way to become involved in their health. Third, it is easily exportable to a range of settings. Primary outcomes included mental functioning, physical functioning, and depressive symptoms.

\section{PATIENTS AND METHODS}

\section{Participants}

Women were eligible for participation in this study if they: (1) had stage 0 , I, or II breast cancer with 10 or fewer positive lymph nodes; (2) were 50 years of age or younger at the time of recruitment; (3) had no history of treatment for other cancers; (4) had recently (within 2 months) completed nonhormonal adjuvant therapy; and (5) were English speaking. This study was performed in accordance with an assurance filed with and approved by the Department of Health and Human Services and had the approval of relevant institutional review boards. All participants signed an informed consent.

Potential participants were identified through nurse referrals of consecutive and potentially eligible patients from hospital medical oncology clinics and physicians' offices in southwestern Pennsylvania. As can be seen in Figure 1, 463 women who responded affirmatively to an interest in the study were contacted by telephone, screened for eligibility, and given more information on the study. Of the 463 women who were contacted, 325 were eligible and $252(78 \%)$ agreed to participate.

Twenty-eight of the women recruited into the study left before the final interview. Two women (assigned to the education arm) died before the end of the study. One woman (assigned to the nutrition arm) was excluded for a protocol violation. The remaining 25 either withdrew or failed to respond to requests for interviews, six from the nutrition arm, 11 from the education arm, and eight from the control arm. Two hundred and twenty-four women completed all three assessments and were included in the analyses presented here.

Analyses were conducted on baseline demographic, medical/ treatment, and primary outcome measures, comparing participants who dropped out before the final follow-up to participants 


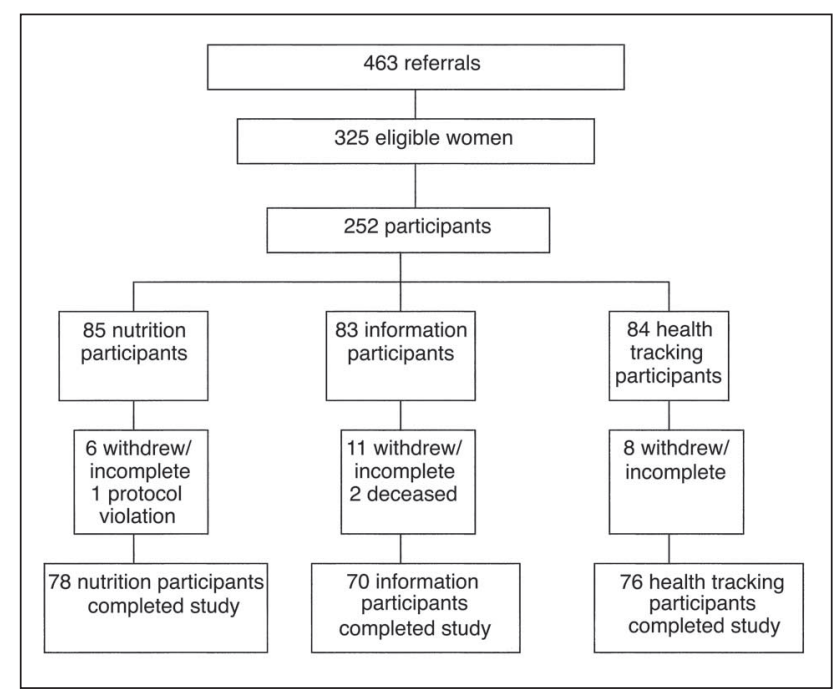

Fig 1. Flow chart of Breast Cancer Recovery Project Participant Accrual and Retention.

who remained enrolled in the trial. There were no significant differences on any of these variables between these two groups, with the exception of age. Women who remained in the study were older (mean age $=44.4$ years for women who remained $v$ mean age $=42.0$ years for women who dropped out; $t=2.38 ; P=.018)$.

The majority of the participants were white, married (with at least one child), well educated, and working full time in positions that were more professional or managerial in nature. In addition, the majority of the women were diagnosed with stage I or II breast cancer, had a lumpectomy and their axillary nodes removed, and received combined radiation and chemotherapy. Column 1 of Table 1 summarizes the demographic, medical, surgical, and treatment characteristics of the participants.

\section{Description of Study}

Participants were randomly assigned either to a control arm, which received standard medical care, or to one of two active treatment arms. Each active treatment arm received a series of four group sessions that met once a month for four consecutive months. Each monthly session lasted two hours. Session size ranged from 2 to 11 participants, averaging 6 across all sessions. Participants in the education arm received information about their disease and treatment, whereas participants in the nutrition arm received information on how to adopt and adhere to a low-fat, high-fruit-and-vegetable eating pattern. Session topics were free standing and rotated on a regular basis across 4-month intervals, which allowed participants to be randomly assigned and immediately placed into the next session that was scheduled. Session topics were chosen based on our interpretation of the prior literature in the area, our prior clinical experience, and our prior experience with randomized trials of this type. All assessments were conducted by trained interviewers using a face-to-face structured interview, either in the participants' homes or at a location of their choosing.

Baseline assessments occurred after consent had been obtained, but before randomization. Follow-up assessments occurred 4 and 13 months later (corresponding to immediate postintervention and 9-months postintervention for participants in the two active arms).

\section{Education Sessions}

The four education sessions were specifically designed to provide information about the psychosocial issues of concern to younger women with early stage breast cancer. Each session was led by two professionals with expertise in the topic of that session. Included among the presenters were a reproductive endocrinologist, a minister, a clinical psychologist, a registered nurse, and several oncology social workers. The sessions were structured in a didactic fashion, beginning with presentation of informational material followed by guided discussion of related topics, and in some cases activities and exercises. Interactions between participants were kept to a minimum. Sessions included "Talking with Children about Cancer," which discussed what to say and not say to children about cancer and how to create a safe environment for them in the midst of all the change; "Life After the Diagnosis: Moving from Darkness to Light," about carrying on with life after the diagnosis and treatment of breast cancer, including strategies for managing stress and anxiety and developing meaning in life; "Relationships and Intimacy," which talked about how to maintain or regain closeness with a partner and ways to talk about the effects of breast cancer in one's life; and a session covering two topics, issues related to the effects of treatment on reproductive status "Hormones and Breast Cancer," and the genetic bases of breast cancer "Basic Factors of Heredity." In addition to the information presented in the session, participants were given related booklets and brochures to take home to read. They were also told of local resources for further information and support. The overall goal of the sessions was to provide information that would reduce participants' uncertainty about their illness and its treatment, to enhance coping in productive ways with the issues and problems confronting them, and to facilitate communication between the participants and their partners.

\section{Nutrition Sessions}

The nutrition sessions were presented by a professional trained in nutritional science. As with the education sessions, each nutrition session included both the presentation of information, guided discussion of related topics, and activities and exercises. The nutritional sessions included "Healthy Cupboards," with information on choosing fruits, vegetables, and low-fat foods and incorporating them into a diet; "What's Cooking," a demonstration of low-fat cooking methods; "Shopping for Success," providing information on the nutritional make-up of a healthy diet and how to shop for it; and "Out on the Town," with information on how to maintain a healthy, low-fat diet while eating out. Additional educational material was provided at each session for participants to take home with them. Women were also asked to keep a four-day food diary, to focus them on their dietary intake and control over it. Emphasis was placed on the helpfulness of accomplishing any change in reducing dietary fat, not necessarily in adopting the suggested dietary changes completely. Each session provided information and encouragement on setting and attaining measurable goals for healthy eating and on the benefits of thinking positively about dealing adaptively with problems in life and living a healthy lifestyle.

\section{Quality Assurance}

Before the start of accrual, each session presenter (or set of presenters) devised an outline covering the points that were to be made during the session. These outlines were then used by the 


\begin{tabular}{|c|c|c|c|c|c|c|c|c|}
\hline \multirow[b]{2}{*}{ Patient Characteristics } & \multirow[b]{2}{*}{ Total Sample } & \multicolumn{3}{|c|}{ Arm } & \multirow[b]{2}{*}{$x^{2}$} & \multirow{2}{*}{$\begin{array}{l}\text { Two-Sided } \\
\text { Significance }\end{array}$} & \multirow[b]{2}{*}{$F$} & \multirow[b]{2}{*}{$P$} \\
\hline & & Nutrition & Education & Control & & & & \\
\hline Mean age, years & 44.2 & 44.2 & 43.7 & 44.6 & & & 0.62 & .54 \\
\hline Race/ethnicity, \% & & & & & 8.9 & 18 & & \\
\hline Caucasian & 94 & 91 & 95 & 98 & & & & \\
\hline African American & 4 & 5 & 5 & 2 & & & & \\
\hline Other & 2 & 4 & - & - & & & & \\
\hline Marital status, \% & & & & & 8.0 & .43 & & \\
\hline Married & 73 & 67 & 82 & 71 & & & & \\
\hline Divorced & 13 & 15 & 8 & 14 & & & & \\
\hline Separated & 2 & 2 & 1 & 4 & & & & \\
\hline Widowed & 2 & 4 & - & 1 & & & & \\
\hline Single, never married & 10 & 12 & 8 & 10 & & & & \\
\hline Children, one or more, \% & 77 & 80 & 75 & 77 & 0.67 & .71 & & \\
\hline Education, \% & & & & & 9.9 & .27 & & \\
\hline High school or GED diploma & 16 & 12 & 17 & 20 & & & & \\
\hline Technical education & 10 & 11 & 7 & 13 & & & & \\
\hline Some college & 23 & 23 & 17 & 27 & & & & \\
\hline College or graduate degree & 51 & 54 & 54 & 49 & & & & \\
\hline Employment, \% & & & & & 3.8 & .88 & & \\
\hline Full-time & 52 & 52 & 51 & 52 & & & & \\
\hline Part-time & 17 & 14 & 19 & 17 & & & & \\
\hline Homemaker & 14 & 15 & 15 & 11 & & & & \\
\hline Unemployed & 18 & 19 & 16 & 20 & & & & \\
\hline Type of employment, \% & & & & & 8.5 & .75 & & \\
\hline Professional & 36 & 38 & 41 & 30 & & & & \\
\hline Managerial & 11 & 11 & 8 & 15 & & & & \\
\hline Clerical or sales & 16 & 12 & 18 & 18 & & & & \\
\hline Crafts, operatives, domestic, other & 7 & 4 & 6 & 4 & & & & \\
\hline Not employed & 30 & 34 & 32 & 30 & & & & \\
\hline Religion, \% & & & & & 2.9 & .94 & & \\
\hline Catholic & 48 & 48 & 51 & 46 & & & & \\
\hline Protestant & 38 & 39 & 36 & 39 & & & & \\
\hline Jewish & 3 & 5 & 2 & 2 & & & & \\
\hline Other & 3 & 4 & 4 & 2 & & & & \\
\hline None & 7 & 5 & 7 & 10 & & & & \\
\hline Household income, \% & & & & & 6.7 & .35 & & \\
\hline$<\$ 24,999$ & 10 & 7 & 9 & 14 & & & & \\
\hline$\$ 25,000-\$ 49,999$ & 26 & 32 & 22 & 23 & & & & \\
\hline$\$ 50,000-\$ 74,999$ & 27 & 29 & 23 & 29 & & & & \\
\hline$>\$ 75,000$ & 37 & 32 & 46 & 34 & & & & \\
\hline Diagnosis and treatment & & & & & 0.556 & .97 & & \\
\hline \multicolumn{9}{|l|}{ Stage, \% } \\
\hline Stage 0 & 11 & 10 & 10 & 12 & & & & \\
\hline Stage 1 & 41 & 39 & 40 & 43 & & & & \\
\hline Stage II & 49 & 51 & 49 & 46 & & & & \\
\hline Mean time since diagnosis, months & 6 & 6 & 6 & 6.5 & & & 0.11 & .90 \\
\hline Surgery, \% & & & & & 3.65 & .46 & & \\
\hline Lumpectomy & 76 & 79 & 69 & 80 & & & & \\
\hline Mastectomy & 18 & 17 & 23 & 14 & & & & \\
\hline Both lumpectomy and mastectomy & 6 & 5 & 8 & 6 & & & & \\
\hline Adjuvant treatment, \% & & & & & 2.12 & .71 & & \\
\hline Radiation & 22 & 24 & 20 & 24 & & & & \\
\hline Chemotherapy & 16 & 15 & 21 & 14 & & & & \\
\hline Both radiation and chemotherapy & 61 & 61 & 59 & 63 & & & & \\
\hline Tamoxifen therapy & 57 & 63 & 55 & 53 & 1.89 & .39 & & \\
\hline
\end{tabular}

presenters as a template during the trial to ensure that a core set of material went out to all participants. Because the groups were dynamic, other issues naturally arose during the sessions that had to be incorporated into the discussion, but presenters were in- structed to cover all of the topics on the outline at each session. Project staff periodically observed the sessions and reported protocol irregularities back to the principal investigator, who then contacted the presenter(s) to correct the problem. 


\section{Measures}

Demographic information was obtained through participants' self-reports. Medical and medical history information was gathered through medical records, surgical records, and participants' self-reports.

\section{Assessment of Knowledge Gained and Participant Evaluation of Trial}

An 11-item nutritional quiz and a 10-item general breast cancer quiz were administered to all participants at each assessment point to measure their knowledge of the information that would be (or was) presented at the intervention sessions. A sample item from the nutritional quiz is, "Which of the following servings of cheese has less than $4 \mathrm{~g}$ of fat?"; a sample item from the general breast cancer quiz is, "True or false... . A couple should agree on a similar coping style and schedule in order to be able to communicate effectively during breast cancer recovery."

In addition, participants completed a brief eight-item questionnaire designed to assess their response to the trial and the trial staff with whom they had contact. For example, participants were asked how much they had benefited from the trial, how pleased they were with the amount of attention they had received from staff members, and how involved they were with the trial.

\section{Dietary Measures}

Given the nature of the nutritional arm, changes in diet were obtained in this trial using a self-report dietary questionnaire and a 4-day food record. Although significant changes in diet did occur, those changes were unrelated to the primary outcome variables of interest, and so cannot account for the findings that are reported here. It is our intention to publish data relating to dietary changes in a separate report.

\section{Outcome Measures}

Depressive symptoms. Depressive symptoms were assessed using an abbreviated, ${ }^{43}$ 10-item version of the Center for Epidemiological Studies Depression Scale, ${ }^{44}$ which has been used successfully in many studies of people with cancer ${ }^{30,45-48}$ (Cronbach $\alpha=.87$ in this sample).

Health-related quality of life. Health-related quality of life (HRQOL) was assessed using the 36-item SF-36 from the Medical Outcome Studies. ${ }^{49,50}$ The survey provides scores on eight scales, which can be combined to create a total physical functioning score (PCS) and a total mental health functioning score (MCS). ${ }^{51}$ The two combined scores were used as the primary HRQOL end points in the present study (PCS $\alpha=.76, \operatorname{MCS} \alpha=.80$ ).

\section{Mediating Measures}

Intrusive thoughts. Intrusive thoughts were measured by the Intrusive Thoughts subscale of the Impact of Events Scale (IES). ${ }^{52}$ The Impact of Events Scale includes items such as "I thought about it when I didn't mean to" and "I had waves of strong feelings about it." A four-point response scale was used, which asked participants to indicate how often each of the experiences occurred. When completing the IES, participants were oriented toward their experiences related to their cancer diagnosis and treatment. In this sample, the Cronbach $\alpha$ for the subscale was .86.

Self-efficacy. A 15-item scale was developed for this study, which asked the participants how confident they were that they would be able to deal successfully with the issues and challenges raised by their diagnosis and treatment. For example, items included questions about their confidence in making sense of their illness, their ability to deal with emotions generated by the illness, and their confidence about being able to communicate effectively about their illness and treatment with family and friends (Cronbach $\alpha=.87$ ).

Cancer concerns. Participants' concerns about their cancer were measured using a 30-item scale adapted from the Profile of Concerns about Breast Cancer Scale developed by Spencer, ${ }^{27}$ designed to measure cancer concerns in a variety of domains of life. Items asked the women to indicate on a scale of 1 to 5 how concerned they were about the impact of the disease and treatment on children and partners, on relationships with family and friends and at work, on sexuality and femininity, and on physical functioning. They were also asked about concerns regarding independence, disease recurrence, and death. Factor analysis of the 30-item scale yielded three distinct factors: issues of femininity (five items, Cronbach's $\alpha=.80$ ); avoidance (five items, Cronbach's $\alpha=.74$ ); and disease impact, recurrence, and mortality (six items, Cronbach's $\alpha=.86$ ).

Self-concept. On the basis of previous work, ${ }^{39,53}$ a nine-item self-concept scale was developed that assessed participants' feelings regarding their physical attractiveness, femininity, and sexual desirability and inhibitions. Items included questions such as "How physically attractive do you feel you are?" "How selfconscious do you feel in groups of women?" and "To what extent do you feel 'not like yourself anymore'?". Cronbach's $\alpha$ for the scale was .88 .

Coping. Participants' illness-related coping responses were measured with an abbreviated version of the situational COPE scale. ${ }^{54}$ The situational version of the COPE consists of a set of brief scales, each measuring a conceptually distinct coping response that the respondent completes with respect to a particular event or situation (in this case, breast cancer). Factor analyses of the COPE have yielded 15 discrete factors. The factors include active coping, planning, positive reframing, restraint, acceptance, humor, religion, use of emotional support, use of instrumental support, self-distraction, denial, venting, substance use, mental disengagement, and behavioral disengagement. For present purposes (in order to reduce participant burden), only the three highest-loading items from each of the 15 factors was administered ( 35 items in all). The average Cronbach's $\alpha$ for the 15 subscales in the present study was .65 .

\section{Statistical Methods}

All women who agreed to random assignment and completed all three assessments were retained in the analysis regardless of their level of group attendance. Although attendance in the nutrition $\operatorname{arm}(\mathrm{M}=2.78)$ was higher than that in the education arm $\left(\mathrm{M}=1.96 ; \mathrm{t}_{154}=3.48 ; P<.01\right)$, there were no significant relationships between attendance and any of the outcome measures assessed (average $P$ across outcomes $>.15$ ). Thus, differences in attendance across arms cannot account for the primary outcomes that are presented. Moreover, despite the difference in group attendance, both arms benefited in appropriate ways from the information that was provided in the group sessions. Women in the education arm improved more on the general breast cancer knowledge test $(M=1.30)$ from pre- to postintervention than women in the nutrition $\operatorname{arm}\left(\mathrm{M}=0.46 ; \mathrm{t}_{154}=-2.71 ; P<.01\right)$, whereas women in the nutrition arm improved more on the nutrition test $(\mathrm{M}=0.61)$ from pre- to postintervention than women in the education $\operatorname{arm}\left(\mathrm{M}=0.10 ; \mathrm{t}_{154}=1.95, P<.06\right)$. Thus, participants in both treatment arms seem to have acquired the information that the intervention presented. It should be noted that changes in knowledge as assessed by our knowledge tests were (with one exception involving nutrition scores and physical functioning at T2) unrelated to the primary outcomes of 
the trial, and so cannot account in and of themselves for the primary outcomes that are reported. In addition, when the quiz scores were entered into the final mediational models that were evaluated, the quiz scores left the results of the final models (presented in Mediation Analyses) generally unchanged.

Before primary analyses, the three groups of participants were compared on baseline demographic, medical, psychosocial predictor, and outcome variables (using analysis of variance for continuous variables and $\chi^{2}$ for categoric variables). No significant differences were found on any of these variables between the three groups at baseline (Tables 1 and 2).

\section{Primary Analyses}

Primary outcome data were analyzed in two steps. First, each primary outcome variable was subjected to a $3 \times 3$ (treatment $\times$ time) multivariate analysis of variance (MANOVA) procedure utilizing all three time points. Second, for those outcomes in which a significant treatment $\times$ time interaction was found, relations were further examined using multiple regression techniques. In each case, dummy variables were created for the two active treatment arms. Primary outcome variables were then regressed onto these dummy coded variables, along with the relevant outcome variable at Time 1 (baseline), in order to examine changes in outcome across time. Separate analyses were performed for Time 2 and Time 3 data.

Finally, regression analyses were conducted in order to determine whether there were any significant differences between the two active treatment arms for any of the primary outcome variables examined.

\section{Mediation Analyses}

Mediational analyses were conducted following procedures outlined by Baron and Kenny. ${ }^{57}$ First, regressions were performed to examine associations between treatment arms and potential mediators, and between potential mediators and relevant outcomes. Potential mediators showing significant associations with at least one treatment arm and at least one relevant outcome were then utilized for subsequent multiple regression analyses. These analyses proceeded in two steps. In step 1, a relevant outcome variable was regressed onto the dummy-coded treatment variables, along with the relevant Time 1 outcome variable, as was done in the primary analyses. In step 2, the residualized scores on the potential mediator (examining change from Time 1 to Time 2 or Time 3, depending on the assessment point being analyzed) were entered into the equation. For each potential mediator, the magnitude and significance of the regression coefficient for the intervention effect in the first equation were compared to the regression coefficient in the second equation, along with the significance of the mediating variable. In addition, Sobel tests (as outlined by Baron and Kenny) were conducted to evaluate the significance of each indirect pathway.

In a final set of analyses, the residualized scores from each mediating variable that provided a significant indirect pathway for at least one intervention effect (as determined by the Sobel test) were simultaneously entered in step 2 to determine the unique contributions of each. These multivariate analyses were again conducted separately for Time 2 and Time 3.

In addition to the primary mediational analyses described in the preceding paragraphs, the effect of the participants' evaluation of the trial was included in a separate analysis, to determine whether these reactions might have had a mediational effect as well. Although the participants in the nutrition arm did report significantly more positive evaluation scores $(\beta=.347, P<.001)$ than participants in

\begin{tabular}{|c|c|c|c|}
\hline & $\begin{array}{l}\text { Baseline } \\
\text { (Time 1) }\end{array}$ & $\begin{array}{l}\text { Postintervention } \\
\text { (Time 2) }\end{array}$ & $\begin{array}{c}\text { Final Follow-Up } \\
\text { (Time 3) }\end{array}$ \\
\hline \multicolumn{4}{|c|}{ Depressive symptoms* } \\
\hline \multicolumn{4}{|c|}{ Nutrition } \\
\hline Mean & 6.74 & 5.70 & 4.36 \\
\hline SD & 5.94 & 5.45 & 4.49 \\
\hline No. of patients & 78 & 78 & 78 \\
\hline \multicolumn{4}{|l|}{ Education } \\
\hline Mean & 5.83 & 5.65 & 5.07 \\
\hline SD & 5.32 & 5.53 & 4.99 \\
\hline No. of patients & 69 & 69 & 69 \\
\hline \multicolumn{4}{|l|}{ Control } \\
\hline Mean & 6.70 & 6.87 & 6.88 \\
\hline $\mathrm{SD}$ & 5.84 & 5.84 & 6.19 \\
\hline No. of patients & 76 & 76 & 76 \\
\hline \multicolumn{4}{|l|}{ Physical functioningt } \\
\hline \multicolumn{4}{|l|}{ Nutrition } \\
\hline Mean & 50.38 & 53.59 & 53.90 \\
\hline SD & 8.26 & 6.18 & 5.55 \\
\hline No. of patients & 78 & 78 & 78 \\
\hline \multicolumn{4}{|l|}{ Education } \\
\hline Mean & 49.21 & 52.03 & 55.11 \\
\hline SD & 8.19 & 7.02 & 7.12 \\
\hline No. of patients & 70 & 70 & 70 \\
\hline \multicolumn{4}{|l|}{ Control } \\
\hline Mean & 49.16 & 50.73 & 50.93 \\
\hline SD & 8.26 & 9.07 & 9.14 \\
\hline No. of patients & 76 & 76 & 76 \\
\hline \multicolumn{4}{|l|}{ Mental functioningt } \\
\hline \multicolumn{4}{|l|}{ Nutrition } \\
\hline Mean & 46.91 & 50.38 & 51.26 \\
\hline SD & 11.18 & 9.06 & 8.27 \\
\hline No. of patients & 78 & 78 & 78 \\
\hline \multicolumn{4}{|l|}{ Education } \\
\hline Mean & 45.63 & 50.47 & 48.64 \\
\hline SD & 10.77 & 9.13 & 10.72 \\
\hline No. of patients & 70 & 70 & 70 \\
\hline \multicolumn{4}{|l|}{ Control } \\
\hline Mean & 45.76 & 49.27 & 49.48 \\
\hline SD & 10.69 & 9.06 & 8.27 \\
\hline No. of patients & 76 & 76 & 76 \\
\hline \multicolumn{4}{|c|}{ 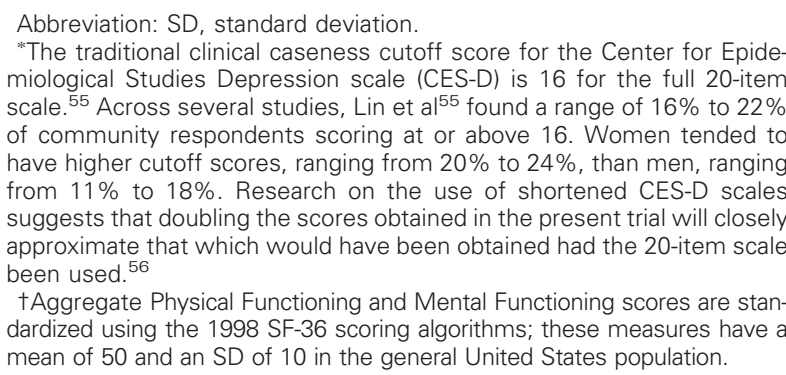 } \\
\hline
\end{tabular}

the control arm (participants in the control and education arm did not differ), there were no significant relationships between evaluation scores and primary outcomes. As a result, these evaluation scores were not included in any further analysis.

Finally we should note explicitly that the present analyses did not attempt to identify moderators of treatment effects because 
discussion of moderator variables is beyond the scope of the present article. If interesting and/or important moderator variables emerge from later analyses they will be reported on separately.

\section{Power}

Power analyses based on the sample size presented here confirmed that, using the planned analyses, the study retained $99 \%$ power to identify moderate effect sizes ( $\mathrm{f} 2=0.15)$ with an $\alpha$ of .05 .

\section{RESULTS}

\section{Primary Outcomes}

Means and standard deviations (SDs) for the three primary outcome measures across the three assessment points are presented in Table 2.

Overall, participants exhibited significantly fewer depressive symptoms over time, $\left(F_{2440}=4.18 ; P<.02\right)$. There was also a significant treatment $\times$ time interaction $\left(F_{4440}=2.45 ; P<.05\right)$. Follow-up regression analyses revealed that neither the nutrition arm nor the education arm differed from the control arm at Time 2 (all $P>.09$ ). At Time 3, participants in the nutrition arm reported significantly fewer depressive symptoms $(\beta=-.23 ; P<.001)$, and the education arm marginally fewer depressive symptoms $(\beta=-.12, P<.08)$, than did participants in the control arm. The difference between the two active treatment arms was not significant $(P>.05)$.

\section{Physical Functioning}

Overall, levels of physical functioning improved over time $\left(F_{2442}=29.35 ; P<.001\right)$. There was also a significant treatment $\times$ time interaction $\left(F_{4442}=3.35 ; P<.02\right)$. Follow-up regression analyses revealed that the nutrition arm had better physical functioning than the control arm at Time $2(\beta=.13 ; P<.04)$, but that physical functioning in the education arm and control arm were no different at Time $2(P>.50)$. The difference between the two active treatment arms at Time 2 was not significant $(P>.05)$. At Time 3, physical functioning was significantly better in both the nutrition $\operatorname{arm}(\beta=.15 ; P<.02)$, and the education arm $(\beta=.25 ; P<.001)$, than it was in the control arm. The difference between the two active treatment arms at Time 3 was not significant $(P>.05)$.

\section{Mental Health Functioning}

Overall, levels of mental health functioning improved over time $\left(F_{2442}=23.11 ; P<.001\right)$. There was no treatment $X$ time interaction $(F<.99)$. Thus, the interventions failed to have a significant impact on mental health functioning.

\section{Mediational Pathways}

The interventions impacted depressive symptoms at Time 3 only. Of the mediators examined, intrusive thoughts, self-efficacy expectations, cancer concerns regarding recurrence and mortality, and self-concept perceptions all fit the preliminary criteria outlined by Baron and
Kenny for inclusion as potential mediators, as did the two coping strategies of planning and denial. As shown in Table 3, the effects of the education and nutrition interventions on depressive symptoms were reduced (sometimes substantially) when residualized intrusive thoughts, self-efficacy expectations, cancer concerns regarding recurrence and mortality, self-concept perceptions, planning, or denial were entered into the second equation. Table 4 presents associations between the interventions and mediators retained in the final models.

Calculation of the Sobel test on these mediators showed that the education intervention exerted significant indirect effects through intrusive thoughts $(Z=-2.44 ; P<.02)$, cancer concerns regarding recurrence and mortality $(Z=-2.52 ; P<.02)$, self-concept perceptions $(Z=-3.32$; $P<.001)$, and planning coping $(Z=-4.12 ; P<.001)$ on depressive symptoms at Time 3 . Sobel tests also showed that the nutrition intervention exerted significant indirect effects on depressive symptomatology at Time 3 through intrusive thoughts $(Z=-3.04 ; P<.005)$, self-efficacy expectancies $(Z=-2.82 ; P<.005)$, cancer concerns regarding recurrence and mortality $(Z=-2.30 ; P<.03)$, self-concept perceptions $(Z=-3.26 ; P<.002)$, and denial coping $(Z=3.23 ; P<.001)$.

To evaluate the unique contribution of each mediator to depressive symptoms at Time 3, one last model was evaluated that simultaneously entered all of the potential mediators (given in Equation 3 for depressive symptoms in Table 3). Of the potential mediators examined, only intrusive thoughts, self-concept perceptions, and self-efficacy expectations emerged as independent, significant mediators of depressive symptoms at Time 3. More intrusive thoughts, lower self-concept perceptions, and lower selfefficacy expectations were associated with greater depressive symptoms. Collectively, these independent mediators accounted for $99 \%$ of the variance in the direct relationships between the interventions and depressive symptoms at Time 3.

\section{Physical Functioning}

Physical functioning at Time 2 was impacted by the nutrition intervention only. Of the mediators examined, only intrusive thoughts and self-concept perceptions fit the preliminary criteria outlined by Baron and Kenny for inclusion as potential mediators. As shown in Table 3, the effects of the nutrition intervention became nonsignificant when either residualized intrusive thoughts or self-concept perceptions were entered into the second equation, whereas both mediators remained significant.

Calculation of the Sobel test on these two mediators showed that the nutrition intervention exerted a marginally significant indirect effect through self-concept perceptions $(Z=1.88 ; P<.06)$ on physical functioning at Time 2 . The indirect path through intrusive thoughts was not significant $(Z=1.33, P<.10)$. Because there was only one significant 
Table 3. Pathways by Which Interventions Affect Depressive Symptoms and Physical Functioning*

\begin{tabular}{|c|c|c|c|c|}
\hline & $\beta$ & $F$ test & $P$ & $R^{2}$ \\
\hline \multicolumn{5}{|l|}{ Depressive symptoms at final follow-up (Time 3) } \\
\hline Equation 1, baseline depressive symptoms & .50 & 8.87 & $<.001$ & 0.293 \\
\hline Nutrition & -.23 & -3.45 & .001 & \\
\hline Education & -.12 & -1.78 & .077 & \\
\hline Equation 2, baseline depressive symptoms & .44 & 48.66 & $<.001$ & 0.403 \\
\hline Intrusive thoughts residualized & .41 & 40.10 & $<.001$ & \\
\hline Nutrition & -.13 & 4.54 & .034 & \\
\hline Education & -.05 & 0.71 & .400 & \\
\hline Equation 2, baseline depressive symptoms & .45 & 57.31 & $<.001$ & 0.415 \\
\hline Self-efficacy residualized & -.46 & 45.10 & $<.001$ & \\
\hline Nutrition & -.14 & 5.48 & .020 & \\
\hline Education & -.10 & 2.52 & .114 & \\
\hline Equation 2, baseline depressive symptoms & .44 & 41.37 & $<.001$ & 0.390 \\
\hline Cancer concern regarding recurrence/mortality residualized & .42 & 31.19 & $<.001$ & \\
\hline Nutrition & -.19 & 6.86 & .10 & \\
\hline Education & -.05 & 0.42 & .518 & \\
\hline Equation 2, baseline depressive symptoms & .40 & 46.33 & $<.001$ & 0.418 \\
\hline Self-concept residualized & -.47 & 40.25 & $<.001$ & \\
\hline Nutrition & -.13 & 4.62 & .033 & \\
\hline Education & -.06 & 0.93 & .335 & \\
\hline Equation 2, baseline depressive symptoms & .46 & 58.48 & $<.001$ & 0.306 \\
\hline Planning coping residualized & .13 & 3.84 & .051 & \\
\hline Nutrition & -.22 & 10.82 & .001 & \\
\hline Education & -.10 & 2.48 & .117 & \\
\hline Equation 2, baseline depressive symptoms & .45 & 64.90 & $<.001$ & 0.351 \\
\hline Denial coping residualized & .21 & 11.74 & .001 & \\
\hline Nutrition & -.20 & 9.72 & .002 & \\
\hline Education & -.10 & 2.31 & .130 & \\
\hline \multicolumn{5}{|l|}{ Depressive symptoms at final follow-up (Time 3) } \\
\hline Equation 3, baseline depressive symptoms & .32 & 18.71 & $<.001$ & 0.556 \\
\hline Intrusive thoughts residualized & .25 & 9.19 & .003 & \\
\hline Self-efficacy residualized & -.18 & 4.33 & .039 & \\
\hline Cancer concerns regarding recurrence/mortality residualized & .15 & 2.77 & .98 & \\
\hline Self-concept residualized & -.34 & 14.67 & $<.001$ & \\
\hline Planning coping residualized & -.07 & 1.01 & .318 & \\
\hline Denial coping residualized & .009 & 0.02 & .894 & \\
\hline Nutrition & -.05 & 0.53 & .469 & \\
\hline Education & .004 & 0.003 & .957 & \\
\hline \multicolumn{5}{|l|}{ Physical functioning at postintervention (Time 2) } \\
\hline Equation 1, baseline physical functioning & .52 & 9.16 & $<.001$ & 0.284 \\
\hline Nutrition & 13 & 2.07 & .040 & \\
\hline Equation 2, baseline physical functioning & .50 & 83.11 & $<.001$ & 0.311 \\
\hline Intrusive thoughts residualized & -.20 & 7.57 & .006 & \\
\hline Nutrition & .11 & 2.76 & .098 & \\
\hline Equation 2, baseline physical functioning & .52 & 82.44 & $<.001$ & 0.305 \\
\hline Self-concept residualized & .20 & 5.61 & .019 & \\
\hline Nutrition & .09 & 2.00 & .159 & \\
\hline \multicolumn{5}{|l|}{ Equation 3, same as Equation 2 for self-concept residualized $t$} \\
\hline \multicolumn{5}{|l|}{ Physical functioning at final follow-up (Time 3) } \\
\hline Equation 1, baseline physical functioning & .50 & 8.73 & $<.001$ & 0.297 \\
\hline Nutrition & .15 & 2.33 & .021 & \\
\hline Education & .25 & 3.91 & $<.001$ & \\
\hline Equation 2 , baseline physical functioning & .48 & 73.04 & $<.001$ & 0.327 \\
\hline Intrusive thoughts residualized & -.18 & 6.85 & .009 & \\
\hline Nutrition & .11 & 2.80 & .096 & \\
\hline Education & .23 & 11.86 & .001 & \\
\hline Equation 2, baseline physical functioning & .47 & 69.64 & $<.001$ & 0.342 \\
\hline Self-efficacy residualized & .25 & 12.33 & .001 & \\
\hline Nutrition & .11 & 2.97 & .006 & \\
\hline Education & .24 & 14.07 & $<.001$ & \\
\hline \multicolumn{5}{|c|}{ (continued on following page) } \\
\hline
\end{tabular}




\begin{tabular}{|c|c|c|c|c|}
\hline & $\beta$ & $F$ test & $P$ & $R^{2}$ \\
\hline \multicolumn{5}{|l|}{ Physical functioning at final follow-up (Time 3) } \\
\hline Equation 2, baseline physical functioning & .41 & 42.87 & $<.001$ & 0.361 \\
\hline Cancer concerns regarding recurrence/mortality residualized & -.37 & 23.11 & $<.001$ & \\
\hline Nutrition & .10 & 1.78 & .185 & \\
\hline Education & .20 & 7.53 & .007 & \\
\hline Equation 2, baseline physical functioning & .48 & 70.09 & $<.001$ & 0.324 \\
\hline Self-concept residualized & .22 & 7.49 & .007 & \\
\hline Nutrition & .10 & 2.27 & .133 & \\
\hline Education & .22 & 11.07 & .001 & \\
\hline Equation 2 , baseline physical functioning & .48 & 67.91 & $<.001$ & 0.315 \\
\hline Planning coping & -.15 & 5.71 & .02 & \\
\hline Nutrition & .14 & 4.57 & .034 & \\
\hline Education & .23 & 12.71 & $<.001$ & \\
\hline Equation 2, baseline physical functioning & .48 & 69.95 & $<.001$ & 0.315 \\
\hline Denial coping & -.15 & 5.71 & .018 & \\
\hline Nutrition & .13 & 4.13 & .043 & \\
\hline Education & .24 & 13.92 & $<.001$ & \\
\hline Equation 3 , baseline physical functioning $\ddagger$ & .40 & 36.60 & $<.001$ & 0.389 \\
\hline Intrusive thoughts residualized & 0.00 & 0.00 & .999 & \\
\hline Self-efficacy residualized & .16 & 3.49 & .097 & \\
\hline Cancer concerns regarding recurrence/mortality residualized & -.25 & 6.58 & .011 & \\
\hline Self-concept residualized & .15 & 2.50 & .116 & \\
\hline Nutrition & .05 & 0.46 & .499 & \\
\hline Education & .19 & 6.48 & .012 & \\
\hline \multicolumn{5}{|c|}{$\begin{array}{l}\text { Abbreviation: } \beta \text {, standardized beta. } \\
\text { "Table } 1 \text { includes only those mediators that met the Baron and Kenny }{ }^{57} \text { criteria for mediation in preliminary analyses. } \\
\text { †The indirect path through intrusive thoughts was not significant as determined by the Sobel test. As a result, Equation } 3 \text { for physical functioning at Time } \\
2 \text { only included one mediator, self-concept perceptions. This renders Equation } 3 \text { identical to the model specified by Equation } 2 \text { that contains self-concept } \\
\text { perceptions as the mediator. } \\
\text { fThe indirect paths through planning coping and denial coping were not significant as determined by the Sobel test. Equation } 3 \text { for physical functioning at } \\
\text { Time } 3 \text { includes only those mediators that were significant or marginally significant in prior testing. }\end{array}$} \\
\hline
\end{tabular}

mediator of Time 2 physical functioning effects, no subsequent simultaneous model was tested.

Both interventions significantly impacted physical functioning at Time 3. Of the mediators examined, intrusive thoughts, self-efficacy expectations, cancer concerns regarding recurrence and mortality, self-concept perceptions, planning coping, and denial coping all fit the preliminary criteria outlined by Baron and Kenny for inclusion as potential mediators. As shown in Table 3, the effects of the education and nutrition interventions on physical functioning were reduced when residualized intrusive thoughts, self-efficacy expectations, cancer concerns regarding recurrence and mortality, selfconcept perceptions, planning, or denial were entered into the second equation, more so for the nutrition than the education intervention.

Calculation of the Sobel test on these mediators showed that the education intervention exerted significant indirect effects through cancer concerns regarding recurrence and mortality $(Z=2.49 ; P<.02$ and marginally significant indirect effects through intrusive thoughts $(Z=1.86 ; P<.07)$ and self-concept perceptions $(Z=1.82 ; P<.07)$. The indirect paths through self-efficacy expectancies and planning cop- ing were not significant. Sobel tests also showed that the nutrition intervention exerted significant indirect effects through intrusive thoughts $(Z=2.14 ; P<.04)$, cancer concerns regarding recurrence and mortality $(Z=2.39 ; P<.03)$, self-concept perceptions $(Z=2.18 ; P<.03)$, and self-efficacy expectancies $(Z=2.23 ; P<.03)$. The indirect path through denial was not significant.

To evaluate the unique contribution of the potential mediators to physical functioning at Time 3, one last model (shown in Equation 3 in Table 3) was evaluated that simultaneously entered all of the potential mediators that had been identified. The results of this analysis revealed that cancer concerns regarding recurrence and mortality emerged as the only independent, significant mediator of physical functioning at Time 3, although the independent, indirect pathway through self-efficacy perceptions was also marginally significant. Greater cancer concerns and lower self-efficacy perceptions were associated with less adaptive physical functioning. Collectively, these independent mediators accounted for $93 \%$ of the variance in the direct relationships between the interventions and physical functioning at Time 3. 


\begin{tabular}{|c|c|c|c|c|c|}
\hline Mediators & $\beta$ & F Test & & $P$ & $R^{2}$ \\
\hline \multicolumn{6}{|l|}{ Intervention effects on T2 mediators } \\
\hline \multicolumn{6}{|l|}{ T-2 Intrusive thoughts } \\
\hline Baseline intrusive thoughts & .63 & 160.00 & & $<.001$ & 0.423 \\
\hline Nutrition & -.12 & 4.64 & & .032 & \\
\hline Information & -.02 & 0.10 & & 753 & \\
\hline \multicolumn{6}{|l|}{ T-2 Self-concept } \\
\hline Baseline self-concept & .74 & 288.15 & & $<.001$ & 0.563 \\
\hline Nutrition & .17 & 11.09 & & .001 & \\
\hline Information & .07 & 2.08 & & .151 & \\
\hline \multicolumn{6}{|l|}{ T-2 Self-efficacy } \\
\hline Baseline self-efficacy & .71 & 239.36 & & $<.001$ & 0.512 \\
\hline Nutrition & .11 & 4.54 & & .034 & \\
\hline Information & -.01 & 0.04 & & .840 & \\
\hline \multicolumn{6}{|l|}{ T-2 Cancer concerns regarding recurrence/mortality } \\
\hline Baseline cancer concerns regarding recurrence/mortality & .65 & 115.56 & & $<.001$ & 0.421 \\
\hline Nutrition & -.06 & 0.825 & & .365 & \\
\hline Information & -.11 & 2.36 & & .126 & \\
\hline \multicolumn{6}{|l|}{ T-2 COPE planning } \\
\hline Baseline COPE planning & .55 & 9.86 & & $<.001$ & 0.298 \\
\hline Nutrition & 0.00 & 0.03 & & .977 & \\
\hline Information & -.04 & -.62 & & .533 & \\
\hline \multicolumn{6}{|l|}{ T-2 COPE denial } \\
\hline Baseline COPE denial & .50 & 8.80 & & $<.001$ & 0.256 \\
\hline Nutrition & -.07 & -1.06 & & .289 & \\
\hline Information & -.04 & -.56 & & .574 & \\
\hline \multicolumn{6}{|l|}{ Intervention effects on T3 mediators } \\
\hline \multicolumn{6}{|l|}{ T-3 Intrusive thoughts } \\
\hline Baseline intrusive thoughts & .53 & 92.85 & & $<.001$ & 0.331 \\
\hline Nutrition & -.22 & 12.28 & & .001 & \\
\hline Information & -.17 & 7.15 & & .008 & \\
\hline \multicolumn{6}{|l|}{ T-3 Self-concept } \\
\hline Baseline self-concept & .69 & 209.69 & & $<.001$ & 0.505 \\
\hline Nutrition & 0.21 & 14.85 & & $<.001$ & \\
\hline Information & .14 & 6.13 & & .014 & \\
\hline \multicolumn{6}{|l|}{ T-3 Self-efficacy } \\
\hline Baseline self-efficacy & .63 & 145.33 & & $<.001$ & 0.409 \\
\hline Nutrition & .19 & 9.80 & & .002 & \\
\hline Information & .05 & 0.797 & & .373 & \\
\hline \multicolumn{6}{|l|}{ T-3 Cancer concerns regarding recurrence/mortality } \\
\hline Baseline cancer concerns regarding recurrence/mortality & .56 & 80.20 & & $<.001$ & 0.349 \\
\hline Nutrition & -.19 & 6.99 & & .009 & \\
\hline Information & -.22 & 8.81 & & .003 & \\
\hline \multicolumn{6}{|l|}{ T-3 COPE planning } \\
\hline Baseline COPE planning & .36 & 5.76 & & $<.001$ & 0.143 \\
\hline Nutrition & -.11 & -1.52 & & .130 & \\
\hline Information & -.16 & -2.21 & & .028 & \\
\hline \multicolumn{6}{|l|}{ T-3 COPE denial } \\
\hline Baseline COPE denial & .41 & 6.70 & & $<.001$ & 0.182 \\
\hline Nutrition & -.14 & -2.03 & & .044 & \\
\hline Information & -.08 & -1.10 & & .274 & \\
\hline Mediators & Outcome & $\beta$ & $F$ test & $P$ & $R^{2}$ \\
\hline \multicolumn{6}{|l|}{ T2 mediator effects on outcomes } \\
\hline T-2 Intrusive thoughts & PCS T-2 & -.233 & 9.81 & .002 & 0.311 \\
\hline T-2 Self-concept & PCS T-2 & .228 & 7.86 & .005 & 0.306 \\
\hline T-2 Self-efficacy & PCS T-2 & .120 & 2.27 & .134 & 0.285 \\
\hline T-2 Cancer concerns regarding recurrence/mortality & PCS T-2 & -.243 & 7.68 & .006 & 0.272 \\
\hline T-2 COPE planning & PCS T-2 & -.040 & 0.353 & .553 & 0.277 \\
\hline T-2 COPE denial & PCS T-2 & -.043 & 0.433 & .511 & 0.279 \\
\hline \multicolumn{6}{|c|}{ (continued on following page) } \\
\hline
\end{tabular}




\begin{tabular}{|c|c|c|c|c|c|}
\hline Mediators & Outcome & $\beta$ & F Test & $P$ & $R^{2}$ \\
\hline \multicolumn{6}{|l|}{ T3 mediator effects on outcomes } \\
\hline \multirow[t]{2}{*}{ T-3 Intrusive thoughts } & CES-D T-3 & .445 & 49.02 & .001 & 0.390 \\
\hline & PCS T-3 & -.228 & 11.38 & .001 & 0.290 \\
\hline \multirow[t]{2}{*}{ T-3 Self-concept } & CES-D T-3 & -.509 & 50.01 & .001 & 0.405 \\
\hline & PCS T-3 & .270 & 11.89 & .001 & 0.297 \\
\hline \multirow[t]{2}{*}{ T-3 Self-efficacy } & CES-D T-3 & -.486 & 52.96 & .001 & 0.399 \\
\hline & PCS T-3 & .268 & 13.61 & .001 & 0.300 \\
\hline \multirow[t]{2}{*}{ T-3 Cancer concerns regarding recurrence/mortality } & CES-D T-3 & .456 & 37.16 & .001 & 0.362 \\
\hline & PCS T-3 & -.427 & 31.44 & .001 & 0.338 \\
\hline \multirow[t]{2}{*}{ T-3 COPE planning } & CES-D T-3 & .146 & 5.15 & .024 & 0.272 \\
\hline & PCS T-3 & -.180 & 8.57 & .004 & 0.280 \\
\hline \multirow[t]{2}{*}{ T-3 COPE denial } & CES-D T-3 & .235 & 14.63 & .001 & 0.322 \\
\hline & PCS T-3 & -.172 & 7.30 & .007 & 0.277 \\
\hline
\end{tabular}

\section{DISCUSSION}

To our knowledge, the present trial is the first large clinical trial to target younger women diagnosed with breast cancer who are in the process of completing nonhormonal adjuvant treatment, and thereby transitioning from patient to survivor status. There are four points to make about the findings from this trial. First, both interventions effectively enhanced adjustment. By the time of the last follow-up, participants assigned to the nutrition arm had significantly fewer depressive symptoms and better physical functioning than controls. Participants assigned to the education arm also had significantly better physical functioning and marginally fewer depressive symptoms than controls.

It is of interest and somewhat surprising that the interventions impacted depressive symptoms, but did not affect mental health functioning, as assessed by the MCS. This is even more surprising given that correlations between the Center for Epidemiological Studies Depression scale (CES-D) and MCS hovered in the mid-70s across the three assessment points. Apparently, it was some nonoverlapping variance assessed by the CES-D that was being impacted by the interventions. Consistent with this reasoning, when changes in mental health functioning were entered into the models in which the treatment effects on depressive symptoms were evaluated, the significant intervention effects on depressive symptoms remained unchanged. In order to understand more fully which aspect of depressive symptoms was being affected, item by item analyses of the CES-D were conducted. The nutrition arm had pervasive effects on most aspects of depressive symptoms that were assessed, but the effects were considerably more pronounced for those items tapping into what have been called motivational or somatic issues (eg, "I felt that every- thing I did was an effort" and "I had trouble keeping my mind on what I was doing") rather than items that were affective (eg, "I felt depressed") or social (eg, "I felt lonely") in nature. The effects of the education intervention were more limited to the motivational items. Thus, for both arms it was the motivational items that seemed to be most impacted by the intervention. We find these findings noteworthy because other research has shown that it is the motivational component of depression that is most highly linked with adverse outcomes. ${ }^{58,59}$ Future research should be sensitive to the fact that psychosocial interventions may be more likely to impact some aspects of mental health functioning than others.

Second, the effects of the interventions grew stronger over time. That is, the only significant effect observed when the interventions ended (at Time 2) was for the nutrition arm on physical functioning. That effect became stronger across time, and significant associations between depressive symptoms and the education and nutrition arms emerged. These "sleeper" effects are interesting because the effects of most psychosocial interventions become weaker rather than stronger over time. It remains unclear why the impact of the interventions increased, but the fact that they did certainly seems worthy of future investigation.

Third, it was possible to identify some of the potential mediators underlying the intervention effects. Of the mediators examined, it appeared that the interventions primarily benefited women by enhancing their self-efficacy expectations, reducing some of their cancer concerns regarding future morbidity and mortality, lessening their intrusive thoughts about the illness, and by buffering their self-concept perceptions. Although the impact of these mediators varied somewhat across outcomes and across intervention arms, they played important unique roles in the intervention effects that emerged. 
We should recognize that there are many variables that have the potential to explain the effects of our interventions. In this article, we chose to focus on one particular set of variables - constructs that we thought our interventions were targeting. Although some of these variables achieved a level of statistical significance, it is not clear that these are the most important explanations for the effects of the interventions. Nor is it clear that the set of potential mediators we examined are the same set of variables that all researchers would have included. At a minimum, we can say that our interventions had the significant effect on the mediators that they did, and that the mediators that we examined may be important ends in and of themselves. At a maximum, we have identified important mechanisms by which the interventions influenced well-being. Knowledge of mediating variables is important because it can suggest ways that future interventions might be developed to focus on the variables most responsible for change.

Finally, it is noteworthy that the education and nutrition interventions had the impact that they did. Each involved only four sessions, a total of 8 hours. Yet these interventions had a substantial impact on a wide variety of variables, taking into account both primary outcomes and mediators. Why? In our view, the answer lies in what it is that makes this psychosocial trial unique. First, most interventions target women of all ages. The present intervention explicitly targeted a subgroup of women-those who were younger in age. Perhaps interventions are more useful if they take into account the needs of particular subgroups of women. Second, most interventions are targeted to occur early in the treatment regimen, at the time of initial diagnosis and onset of treatment. The present interventions were targeted to occur when active nonhormonal treatment was ending. Perhaps interventions that are enacted at the end of treatment reach patients at a more optimal time, when they are better able to attend to and process the information and skills that are being offered. Perhaps the heightened distress, uncertainty, and shock that accompany the time surrounding initial diagnosis simply lessens the impact that interventions might have otherwise.

An alternative possibility is that patients benefit from both early-occurring and late-occurring interventions, but for different reasons and for differing lengths of time. Perhaps multiple interventions are required. One set might be targeted to occur around the time of diagnosis and onset of treatment, and would be designed to assist patients to cope in the short run with the events that are happening. A second set of interventions might be targeted to occur around the time contact with medical staff is ending, and would be designed to assist patients to have something longer term to rely on as they struggle to normalize their lives. Although these ideas are speculative, they merit exploration in future trials.

This study also has several limitations that should be mentioned explicitly. First, compliance with treatment ses- sions was higher in the nutrition arm than in the education arm. Although not an aim of the present trial, this difference does make it difficult to compare the efficacy of the two arms with each other. Second, the present trial focused on women with early-stage disease. It is unclear whether similar findings would emerge among patients with more advanced disease. Third, the amount of interest in the trial shown by the participants differed across treatment arms. Although our findings remained unaltered when participants' ratings of the trial were controlled statistically, we cannot rule out the possibility that differential interest in the trial in some way impacted the results. Finally, the trial largely involved women who were white and middle-class. Thus, the extent to which these findings generalize to a more diverse group of women is not known. These limitations should be borne in mind when evaluating the significance of the results.

In summary, we have shown that two different psychosocial interventions targeting younger women completing nonhormonal adjuvant therapy can have a beneficial effect on downstream physical functioning and depressive symptoms. The fact that the interventions impacted on depressive symptoms is particularly noteworthy. Although studies examining the impact of depression and depressive symptoms on cancer morbidity and mortality are decidedly mixed, ${ }^{10,60-64}$ at least one recent epidemiologic study ${ }^{65}$ found that women with early stage breast cancer who had postoperative depression were at significantly higher risk of mortality than those who were not depressed. To the extent that depression and/or depressed symptoms are in fact linked to more adverse health outcomes, the impact of the interventions described here may extend well beyond those examined in this study.

\section{Acknowledgment}

We would like to thank the women who agreed to participate in this project. Without their devotion of time and effort, the information provided by the trial would not have been possible.

\section{Authors' Disclosures of Potential Conflicts of Interest}

The following authors or their immediate family members have indicated a financial interest. No conflict exists for drugs or devices used in a study if they are not being evaluated as part of the investigation. Research Funding: William Scott Pappert, University of Pittsburgh. For a detailed description of this category, or for more information about ASCO's conflict of interest policy, please refer to the Author Disclosure Declaration and Disclosures of Potential Conflicts of Interest found in Information for Contributors in the front of each issue. 


\section{REFERENCES}

1. Hewitt M, Herdman R, Holland J: Meeting Psychosocial Needs of Women With Breast Cancer: National Cancer Policy Board, Institute of Medicine and National Research Council. Washington, DC, The National Academies Press, 2004, pp 95-132

2. Polinsky ML, Fred C, Ganz PA: Qualitative and qualitative assessment of a case management program for cancer patients. Health Soc Work 16:176-183, 1991

3. Edmonds C, Lockwood G, Cunningham A: Psychological response to long term group therapy: A randomized trial with metastatic breast cancer patients. Psychooncology 8:74-91, 1999

4. Gellert GA, Maxwell RM, Siegel BS: Survival of breast cancer patients receiving adjunctive psychosocial support therapy: A 10-year follow-up study. J Clin Oncol 11:66-69, 1993

5. Morgenstern H, Gellert GA, Walter SD, et al: The impact of a psychosocial support program on survival with breast cancer. J Chronic Dis 37:273-282, 1984

6. Samarel N, Fawcett J, Tulman L: Effect of support groups with coaching on adaptation to early stage breast cancer. Res Nurs Health 20 : 15-26, 1997

7. Spiegel D, Bloom J: Group therapy and hypnosis reduce metastatic breast carcinoma pain. Psychosom Med 45:333-339, 1983

8. Spiegel D, Bloom JR, Kraemer HC, et al: Effect of psychosocial treatment on survival of patients with metastatic breast cancer. Lancet 14:888-890, 1989

9. Spiegel D, Morrow GR, Classen C, et al: Group psychotherapy for recently diagnosed breast cancer patients: A multicenter feasibility study. Psychooncology 8:482-493, 1999

10. Goodwin PJ, Leszcz M, Ennis M, et al: The effect of group psychosocial support on survival in metastatic breast cancer. N Engl J Med 345: 1719-1725, 2001

11. Badger TA, Braden CJ, Meshel M: Depression burden, self-help interventions and side effects experience in women receiving treatment for breast cancer. J Psychosoc Oncol 28: 567-574, 2001

12. Simpson JSA, Carlson LE, Beck CA, et al: Effects of a brief intervention on social support and psychiatric morbidity in breast cancer patients. Psychooncology 11:282-294, 2002

13. Helgeson VS, Cohen S, Schulz R, et al: Education and peer discussion group interventions and adjustment to breast cancer. Arch Gen Psychiatry 56:340-347, 1999

14. Helgeson VS, Cohen $S$, Schulz R, et al: Long-term effects of educational and peer discussion group interventions adjustment to breast cancer. Health Psychol 20:387-392, 2001

15. Andersen BL, Farrar WB, Golden-Kreutz DM, et al: Psychological, behavioral, and immune changes after a psychological intervention: A clinical trial. J Clin Oncol 22:3570-3580, 2004

16. Baider LA, Kaplan De-Nour A: Breast cancer-A family affair, in Cooper CL (ed): Stress and Breast Cancer. New York, NY, John Wiley \& Sons Inc, 1988, pp 155-170

17. Ganz PA, Lee JJ, Sim MS, et al: Exploring the influence of multiple variables on the rela- tionship of age to quality of life in women with breast cancer. J Clin Epidemiol 45:473-485, 1992

18. Maunsell E, Brisson J, Deschenes L: Psychological distress after initial treatment of breast cancer: Assessment of potential risk factors. Cancer 70:120-125, 1992

19. Goldberg JA, Davidson PM, Murray GD, et al: Psychological morbidity in the first year after breast surgery. Eur J Surg Oncol 18:327-331, 1992

20. Bloom JR, Kessler L: Risk and timing of counseling and support interventions for younger women with breast cancer. J Natl Cancer Inst Monogr 16:199-206, 1994

21. Bloom JR, Steward $S L$, Johnston $M$, et al: Intrusiveness of illness and quality of life in young women with breast cancer. Psychooncology 7:89-100, 1998

22. Bloom JR, Stewart $S L$, Johnston $M$, et al: General and specific measures of quality of life in younger women with breast cancer, in Baum A, Anderson BL (eds): Psychosocial Interventions for Cancer. Washington, DC, American Psychological Association, 2001, pp 37-56

23. Mor V, Malin M, Allen S: Age differences in the psychosocial problems encountered by breast cancer patients. J Natl Cancer Inst Monogr 16:191-197, 1994

24. Schnoll RA, Harlow LL, Stolbach LL, et al: A structural model of the relationships among stage of disease, age, coping, and psychological adjustment in women with breast cancer. Psychooncology 7:69-77, 1998

25. Siegel K, Gluhoski V, Gorey E: Age-related distress among younger women with breast cancer. J Psychosoc Oncol 17:1-20, 1999

26. Wenzel LB, Fairclough DL, Brady M, et al: Age-related differences in the quality of life of breast carcinoma patients after treatment. Cancer 86:1768-1774, 1999

27. Spencer SM, Lehman JM, Wynings $C$, et al: Concerns about breast cancer and relations to psychosocial well-being in a multiethnic sample of early-stage patients. Health Psychol 18:159168, 1999

28. Wang $X$, Cosby LG, Harris MG, et al: Major concerns and needs of breast cancer patients. Cancer Nurs 22:157-163, 1999

29. Arnold EM: The cessation of cancer treatment as a crisis. Soc Work Health Care 29:21-38, 1999

30. Ward SE, Viergutz G, Tormey $\mathrm{D}$, et al: Patients' reactions to completion of adjuvant breast cancer therapy. Nurs Res 41:362-366, 1992

31. Ganz PA, Kwan L, Stanton AL, et al: Quality of life at the end of primary treatment of breast cancer: First results from the Moving Beyond Cancer Randomized Trial. J Natl Cancer Inst 96:376-387, 2004

32. Lethborg CE, Kissane D, Burns WI, et al: Cast Adrift: The experience of completing treatment among women with early stage breast cancer. J Psychosoc Oncol 18:73-90, 2000

33. Baum $A$, Cohen $L$, Hall $M$ : Control and intrusive memories as possible determinants of chronic stress. Psychosom Med 55:274-286, 1993

34. Baum A: Stress, intrusive imagery, and chronic distress. Health Psychol 9:653-675, 1990

35. Cordova MJ, Andrykowski MA, Redd WH, et al: Frequency and correlates of post-traumaticstress-disorder-like symptoms after treatment for breast cancer. J Consult Clin Psychol 63:981986, 1995

36. Epping-Jordan JE, Compas BE, Osowiecki DM, et al: Psychological adjustment in breast cancer: Processes of emotional distress. Health Psychol 18:315-326, 1999

37. Primo K, Compas BE, Oppedisano G, et al: Intrusive thoughts and avoidance in breast cancer: Individual differences and associations with psychological distress. Psychol Health 14:1141 1153, 2000

38. Carver CS, Pozo-Kaderman C, Price AA, et al: Concern about aspects of body image and adjustment to early stage breast cancer. Psychosom Med 60:168-174, 1998

39. Kemeny MM, Wellisch DK, Schain WS: Psychosocial outcome in a randomized surgical trial for treatment of primary breast cancer. Cancer 62:1231-1237, 1988

40. Mock V: Body image in women treated for breast cancer. Nurs Res 42:153-157, 1993

41. Braden $\mathrm{CJ}$, Mishel MH, Longman AJ: Self-help intervention project (SHIP): Women receiving breast cancer treatment. Cancer Pract 6:87-98, 1998

42. Geiger AM, Mullen ES, Sloman PA, et al: Evaluation of a breast cancer patient information program. Eff Clin Pract 3:157-165, 2000

43. Newsom JT, Schulz R: Social support as a mediator in the relation between functional status and quality of life in older adults. Psychol Aging 11:34-44, 1996

44. Radloff LS: The CES-D scale: A self-report depression scale for research in the general population. Appl Psychol Measures 1:385-401, 1977

45. Devins GM, Orme CM, Costello CG: Measuring depressive symptoms in illness populations: Psychometric properties of the Center for Epidemiological Studies Depression (CES-D) scale. Psychol Health 2:139-156, 1988

46. Hann D, Winter K, Jacobsen P: Measurement of depressive symptoms in cancer patients: Evaluation of the Center for Epidemiological Studies Depression Scale (CES-D). J Psychosom Res 46:437-443, 1999

47. Roberts CS, Baile WF, Elkins NW, et al: Effects of interview context on the assessment of mood in breast cancer patients: A replication study. J Psychosoc Oncol 8:33-47, 1990

48. Zonderman $A B$, Costa PT, McCrae RR: Depression as a risk for cancer morbidity and mortality in a nationally representative sample. JAMA 262:1191-1195, 1989

49. Ware JE, Sherbourne CD: The MOS 36Item Short-Form Health Survey (SF-36): I. Conceptual framework and item selection. Med Care 30:473-483, 1992

50. Ware JE, Kosinski M, Bayliss MS, et al: Comparison of methods for scoring and statistical analysis of SF-36 health profiles and summary measures: Summary of results from the Medical Outcomes Study. Med Care 33:AS264AS279, 1995

51. Ware JE, Keller S, Bentler PM, et al: Comparisons of health status measurement models and the validity of SF-36 in Great Britain, Sweden and the USA. Qual Life Res 3:68, 1994

52. Horowitz M, Wilner N, Alvarez W: Impact of event scale: A measure of subjective stress. Psychosom Med 41:209-218, 1979 
53. Steinberg MD, Juliano MA, Wise L: Psychological outcome of lumpectomy versus mastectomy in the treatment of breast cancer. Am J Psychiatry 142:34-39, 1985

54. Carver CS, Scheier MF, Weintraub JK: Assessing coping strategies: A theoretically based approach. J Pers Soc Psychol 56:267-283, 1989

55. Lin N, Dean A, Ensel WM: Social Support, Life Events, and Depression. New York, New York, Academic Press, 1986

56. Shrout PE, Yager TJ: Reliability and validity of screening scales: Effect of reducing scale length. J Clin Epidemiol 42:69-78, 1989

57. Baron RM, Kenny DA: The moderatormediator variable distinction in social psychological research: Conceptual, strategic, and statistical considerations. J Pers Soc Psychol 51:1173-1182, 1986

58. Fonda SJ, Herzog AR: Patterns and risk factors of change in somatic and mood symptoms among older adults. Ann Epidemiol 11:361 368, 2001

59. Schulz R, Beach SR, Ives DG, et al: Association between depression and mortality in older adults: The Cardiovascular Health Study. Arch Intern Med 160:1761-1768, 2000

60. Buddeburg $C$, Wolf $C$, Sieber $M$, et al: Coping strategies and course of disease of breast cancer patients: Results of a 3-year longitudinal study. Psychother Psychosom 55:151-157, 1991

61. Gilbar O: The connection between the psychological condition of breast cancer patients and survival: A follow-up after eight years. Gen Hosp Psychiatry 18:266-270, 1996

62. Levy SM, Lee J, Bagley C, et al: Survival hazards analysis in first recurrent breast cancer patients: Seven-year follow-up. Psychosom Med 50:520-528, 1988

63. Watson M, Haviland JS, Greer S, et al: Influence of psychological response on surviva in breast cancer: A population-based cohort study. Lancet 354:1331-1336, 1999

64. Spiegel D: Cancer and depression. $\mathrm{Br} \mathrm{J}$ Psychiatry 168:109-116, 1996

65. Hjerl K, Andersen EW, Keiding N, et al: Depression as a prognostic factor for breast cancer mortality. Psychosomatics 44:24-30, 2003 